\title{
PENGARUH AROMATERAPI LAVENDER TERHADAP PENURUNAN INTENSITAS NYERI PADA PASIEN POST SECTIO CAESAREA DI RUANGAN TRIBRATA RS BHAYANGKARA KOTA BENGKULU
}

\author{
Vellyza Collin', Dian Dwiana Maydinar², Ma'riatul Latifah ${ }^{3}$, \\ ${ }^{1}$ Program Studi S1 Keperawatan STIKES Tri Mandiri Sakti Bengkulu \\ vellyzacolin7@gmail.com
}

\begin{abstract}
Sectio Caesarea (SC) is delivery of the fetus through an abdominal incision. This action will have an impact on the mother, namely post-sectiocaesarea pain. One of the pain management through a nonpharmacological approach is by giving lavender aromatherapy. This study aims to study the effect of lavender aromatherapy on reducing pain intensity in post sectiocaesarea patients in the Tribrata room of Bhayangkara Hospital, Bengkulu City. This study uses a pre-experimental research design using The One Group Pretest Posttest Design. The population in this study were patients who were treated in the Tribrata Room at Bhayangkara Hospital, Bengkulu City in June 2021. The sampling technique in this study used the Accidental Sampling technique, namely taking samples that happened to exist or were available at the research site as many as 16 people. To measure the intensity of pain pre-test and post-test using the observation sheet. The results of the study using the Wilcoxon signed ranks test showed that before giving lavender aromatherapy there were 8 patients (50\%) with severe pain. There were 5 patients (31.2\%) with moderate pain and 3 respondents (18.8\%) with mild pain. while after giving lavender aromatherapy 3 patients (18.8\%) with severe pain. There were 3 patients (18.8\%) with moderate pain and 10 patients $(62.5 \%)$ with mild pain. It can be concluded that there is an effect of lavender aromatherapy on reducing pain intensity in post sectiocaesarea patients at Bhayangkara Hospital, Bengkulu City.
\end{abstract}

Keywords : : LavenderAromatherapy, SectioCaesarea

\begin{abstract}
ABSTRAK
Sectio Caesarea (SC) tindakan melahirkan janin melalui insisi abdomen. Tindakan ini akan berdampak pada ibu yaitu nyeri pasca section caesarea. Salah satu penanggulangan nyeri melalui pendekatan non farmakologi yaitu dengan pemberian aromaterapi lavender. Penelitian ini bertujuan untuk menilai pengaruh aromaterapi lavender terhadap penurunan intensitas nyeri pada pasien post section caesarea di ruanganTribrata RS Bhayangkara Kota Bengkulu. Penelitian ini menggunakan desain penelitian Pre Eksperimental menggunakan The One Group Pretest Postest Design.Populasi dalam penelitian adalah pasien SC di Ruang Tribrata RS Bhayangkara Kota Bengkulu pada bulan Juni 2021. Teknik pengambilan sampel dalam penelitian ini menggunakan teknik Accidental Sampling yaitu pengambilan sampel yang kebetulan ada atau tersedia di tempat penelitian tersebut sebanyak 16 orang. Untuk melakukan pengukuran intensitas nyeripre-test dan post-test menggunakan lembar observasi. Hasil penelitian menggunakan uji Wilcoxon signed ranks test di dapatkan hasil sebelum pemberian aromaterapi lavender terdapat 8 pasien $(50 \%)$ dengan nyeri berat. Terdapat 5 pasien $(31,2 \%)$ dengan nyeri sedang dan 3 responden $(18,8 \%)$ dengan nyeri ringan. sedangkan sesudah dilakukan pemberian aromaterapi lavender3pasien $(18,8 \%)$ dengan nyeri berat. Terdapat 3 pasien $(18,8 \%)$ dengan nyeri sedang dan 10 pasien $(62,5 \%)$ dengan nyeri ringan. Dapat disimpulkan bahwa ada pengaruh aromaterapi lavender terhadap penurunan intensitas nyeri pada pasien post section caesaraea di RS Bhayangkara Kota Bengkulu.
\end{abstract}

Kata Kunci : : Aromaterapi Lavender, Sectio Caesarea 


\section{PENDAHULUAN}

Dalam pencapaian di Sektor Kesehatan Sustainable Development Goals (SDGs)dalam Goals ke-3 membahas mengenai "Menjamin kehidupan yang sehat dan mendorong kesejahteraan bagi semua orang di segala usia pada tahun 2030." Dalam rangka mewujudkan keluarga Indonesia Sehat, Kementrian Kesehatan telah melaksanakan berbagai program dalam bidang kesehatan dengan penurunan Angka Kematian Ibu (AKI) dan mengakhiri kematian bayi dan balita yang dapat dicegah, dengan menurunkan Angka Kematian Neonatal hingga 12 per 1.000 $\mathrm{KH}$ dan Angka Kematian Balita 25 per $1.000 \mathrm{KH}$ dan Akses Kesehatan Reproduksi termasuk Keluarga Berencana (KB).(Kemenkes, 2017).

Prosedur tindakan seksio sesaria kini semakin banyak dilakukan. dibandingkan dengan 15 tahun yang lalu, seksio sesaria menjadi prosedur untuk menyelamatkan kehidupan. Salah satu alasan peningkatan kelahiran dengan bedah Caesar karena sebagian besar persalinansungsang tidak lagi dilakukan melalui persalinan normal persalinan sesar harus dilakukan jika memang benar-benar dibutuhkan (Latief, 2016).

Menurut Sustainable Development Goals (SDGs) Target yang akan di capai adalah untuk mengurangi Angka Kematian Ibu (AKI) secara Global hingga dibawah 70/10.000 kelahiran hidup di tahun 2030 (WHO, 2015). Sedangkan target nasional yaitu menurunkan Angka Kematian Ibu (AKI) menjadi 306/100.000 kelahiran hidup pada tahun 2019 (Kemenkes, 2016).World Health Organization (WHO)tahun 2016 menetapkan standar rata-rata sectio caesarea di sebuah negara adalah 5-15\% per 1000 kelahiran di dunia dan angka persalinan dengan Sectio Caesarea sekitar $10 \%$ sampai $15 \%$ dari semua proses persalinan. Di negara maju seperti Britania Raya angka kejadian Sectio Caesarea sebesar 20\% (Sihombing, 2017).
Berdasarkan data dari Kemenkes RI (2016) angka kejadian Sectio Caesarea di Indonesia persentasenya sebesar $15,3 \%$, diatas standar yang dikeluarkan WHO, yaitu di rumah sakit pemerintah rata-rata persalinan dengan Sectio Caesarea sebesar $11 \%$, sementara di Rumah Sakit Swasta bisa lebih dari 30\% (Pusdatin, 2017). Berdasarkan profil Dinas Kesehatan Provinsi Bengkulu jumlah persalinan sectiocaesar sebanyak 33.854 orang dengan jumlah persalinan tertinggi di Kota Bengkulu sebanya 6.566 orang dan jumlah persalinan terendah di Kabupaten Lebong sebanyak 919 orang (Dinkes Provinsi Bengkulu, 2017).

Persalinan section caesarea juga memiliki dampak yaitu mengalami nyeri skala tinggi selama 24 jam pertama, hal ini terjadi karena tubuh belum dapat menyesuaikan terhadap respon nyeri (Kuswandari, 2016). Banyak ibu yang mengeluh rasa nyeri dibekas jahitan SC. Keluhan ini sebenarnya wajar karena tubuh mengalami luka dan proses penyembuhannya tidak sempurna. Dampak nyeri yang perlu ditanyakan adalah hal-hal yang spesifik seperti pengaruhnya terhadap pola tidur, pola makan, energi, aktifitas keseharian (Zakiyah, 2015).

Nyeri yang dialami pasien post operasi bersifat akut dan harus segera ditangani, Strategi penatalaksanaan nyeri mencakup baik pendekatan farmakologis dan non farmakologis. Semua intervensi akan sangat berhasil bila dilakukan sebelum nyeri menjadi lebih parah dan keberhasilan sering dicapai jika beberapa intervensi diterapkan secara simultan (Nurhayati, Andriani dan Malisa, 2015).

Hampir semua pembedahan mengakibatkan rasa nyeri. Nyeri merupakan pengalaman sensori dan emosional yang tidak menyenangkan akibat dari kerusakan jaringan yang aktual atau potensial. (Brunner \& Suddart, 2013). Nyeri pasca operasi muncul disebabkan oleh rangsangan mekanik luka yang menyebabkan tubuh menghasilkan mediator-mediator kimia nyeri. (Smeltzer 
\& Bare, 2013). Manajemen nonfarmakologi yang sering diberikan antara lain yaitu dengan meditasi, latihan autogenic, latihan relaksasi progresif, guided imagery, nafas ritmik, operant conditioning, biofeedback, membina hubungan terapeutik, sentuhan terapeutik, stimulus kutaneus, hipnosis,musik, accupresure, aromatherapi (Andarmoyo, 2013).

Aromaterapi adalah terapi komplementer dalam praktek keperawatan dan menggunakan minyak esensial dari bau harum tumbuhan untuk mengurangi masalah kesehatan dan memperbaiki kualitas hidup. . Saat aromaterapi dihisap, zat aktif yang terdapat di dalamnya akan merangsang hipotalamus (kelenjar hipofise) untuk mengeluarkan hormone endoprin. Endoprin diketahui sebagai zat yang menimbulkan rasa tenang, relaks, dan bahagia. Aromaterapi yang umumnya digunakan adalah aromaterapi lavender (Widayani, 2016).

- Hasil penelitian Zerlinda (2016) dengan p-value 0,000. Aromaterapi lavender juga menurunkan tingkat intensitas nyeri antara sebelum dan sesudah diberikan aromaterapi lavender pada pasien pasca operasi dengan nilai $\mathrm{p}$-value 0,001 (Argivigiona, 2013). Damawanti (2016) dalam penelitiannya berjudul pengaruh pemberian aromaterapi lavender terhadap intensitas nyeri pada pasien post sectio caesarea di Ruang Ayyub 1 RS Roemani Semarang. Sampel yang digunakan 35 responden. Uji statistik dengan menggunakan uji Wilcoxon Match Paired Test. Denganhasil penelitiannya sebelum tindakan pemberian aromaterapi lavender kategori berat sebanyak 27 responden $(77,1 \%)$ dan sesudah diberikan tindakan pemberian aromaterapi lavender sebagian besar kategori sedang sebanyak 22 responden $(62,9 \%)$. Hasil uji statistik diperoleh p 0,000 $(\alpha<0,05)$.

Berdasarkan penelitian awal di Rumah Sakit Bhayangkara Kota Bengkulu, data yang didapartkan dari Medikal Record (MR) pada Tahun 2020 dari bulan Januari sampai Desember jumlah pasien post sectio caesarea (SC) sebannyak 229 pasien. Sedangkan pada tahun 2021 bulan januari terdapat 7 pasien, bulan februari 5 pasien, bulan maret 8 pasien, dan bulan april 3 pasien.

Berdasarkan hasil pengkajian di Ruang Tribrata Rumah Sakit Bhayangkara Kota Bengkulu pasien post sectio cesarea mengatakan merasakan nyeri pada luka bekas operasi, nyeri seperti ditusuk-tusuk sehingga menimbulkan perasaan sensori emosional tidak menyenangkan akibat dari kerusakan jaringan. Tindakan non farmakologi yang diberikan oleh perawat ruangan hanya teknik relaksasi nafas dalam dan mobilisasi miring kanan dan miring kiri.Pemberian relaksasi aromaterapi untuk mengurangi nyeri belum pernah dilakukan oleh perawat ruangan

Rumusan masalah dalam penelitian ini adalah "adakah pengaruh aromaterapi lavender terhadap penurunan intensitas nyeri pada pasien post sectio caesarea di ruang Tribrata RS Bhayangkara Kota Bengkulu. Tujuan dari penelitian ini Mempelajari pengaruh aromaterapi lavender terhadap penurunan intensitas nyeri pada pasien post sectio caesarea di ruang Tribrata RS Bhayangkara Kota Bengkulu.

\section{METODE}

Penelitian ini dilakukan di Ruangan Tribrata RS Bhayangkara Kota Bengkulu. Pelaksanaan penelitian ini dilaksanakan, Desain penelitian dalam penelitian ini adalah rancangan Pre Eksperimental dengan pendekatan The One Group Pretest Postest Design.Populasi dalam penelitian ini adalah peneliti mengambil populasi pasien post sectiocaesarea yang di rawat di Ruang Tribrata RS Bhayangkara Kota Bengkulu pada Juni 2021. Cara pengambilan sampel menggunakan accidental sampling. Teknik pengumpulan data dengan data primer dan data sekunder. Teknik analisis data dengan univariat, uji normalitas menggunakan uji Shapiro-wilk dan analisis bivariat. 
HASIL

\section{AnalisisUnivariat}

Analisis univariat dilakukan untuk memperoleh gambaran pengaruh aromaterapi lavender terhadap penurunan intensitas nyeri pada pasien post sectio caesarea di Rumah Sakit BhayangkaraKota Bengkulu sebelum dilakukan Intervensi pemberian aromaterapi lavender dan sesudah dilakukan pemberian aromaterapi lavender.

\section{Tabel 1.Gambaran Intensitas Nyeri Sebelum Diberikan Aromaterapi Lavender di RS Bhayangkara Kota Bengkulu}

\begin{tabular}{ccc}
\hline $\begin{array}{c}\text { Tingkat intensitas nyeri sebelum- } \\
\text { diberikan aromaterapi lavender }\end{array}$ & Frekuensi & Persentase (\%) \\
\hline Berat & 8 & 50,0 \\
Sedang & 5 & 31,2 \\
Ringan & 3 & 18,8 \\
\hline Total & 16 & 100,0 \\
\hline
\end{tabular}

Berdasarkan tabel 1 didapatkan bahwa intensitas nyeri sebelum diberikan aromaterapi lavender terdapat pasien nyeri berat berjumlah 8 orang $(50 \%)$, pasien nyeri sedang berjumlah 5 orang $(31,2 \%)$, dan pasien nyeri ringan berjumlah 3 orang $(18,8 \%)$.

Tabel 2. Gambaran Intensitas Nyeri Sesudah Diberikan Aromaterapi Lavender di RS Bhayangkara Kota Bengkulu

\begin{tabular}{ccc}
\hline $\begin{array}{c}\text { Tingkat intensitas nyeri } \\
\text { Sesudah diberikan aromaterapi lavender }\end{array}$ & Frekuensi & Persentase (\%) \\
\hline Berat & 3 & 18,8 \\
Sedang & 3 & 18,8 \\
Ringan & 10 & 62,5 \\
\hline Total & 16 & 100,0 \\
\hline
\end{tabular}

Berdasarkan Tabel 3 didapatkan bahwa intensitas nyeri sesudah diberikan aromaterapi lavender terdapat Pasien nyeri berat berjumlah 3 orang $(18,8 \%)$, pasien nyeri sedang berjumlah 3 orang $(18,8 \%)$, dan pasien nyeri ringan berjumlah 10 orang $(62,5 \%)$.

\section{Uji Normalitas}

Tabel 3. Hasil Uji Normalitas Data

Variabel

Penurunan intenitas nyeri Sebelum Diberikan Aromaterapi Lavender

Penurunan intenitas nyeri Sesudah Diberikan Aromaterapi Lavender

0.248

0.003

Uji Normalitas data dengan uji Shapiro-Wilkdi atas dapat diketahui bahwa penurunan intensitas nyeri sebelum dan sesudah diberikan aromaterapi lavender dengan nilai $\mathrm{p}=0,248$ untuk penurunan intensitas nyeri sebelum diberikan aromaterapi lavender dan 0,003 untuk penurunan intensitas nyeri setelah diberikan aromaterapi lavender, yang berarti nila $\mathrm{p}<$ 0,05 . Artinya kedua kelompok data tersebut tidak berdistribusi normal, sehingga tidak memenuhi syarat untuk dilakukan uji 
Paired sample t-test sehingga akan digunakan uji statistik Wilcoxon Signed Ranks Test

AnalisisBivariat
Analisa bivariat dilakukan dengan tujuan untuk mengetahui interaksi dua variabel yaitu dependen penurunan intensitas nyeri dan independen pemberian aromaterapi lavender.

Tabel 4. Pengaruh Aromaterapi Lavender Terhadap Penurunan Intensitas Nyeri Pada Pasien Post Sectio Caesarea di RS Bhayangkara Kota Bengkulu

\begin{tabular}{cccccc}
\hline Variabel & Rank & $\mathbf{N}$ & Mean Rank & $\boldsymbol{Z}$ & $\mathbf{P}$ \\
\hline Penurunan Intensitas Nyeri & Negatif & 9 & 5.89 & & \\
& Positif & 1 & 2.00 & & \\
& Ties & 6 & & -2.609 & 0,009 \\
\hline Total & \multicolumn{3}{c}{16} & \\
\hline
\end{tabular}

Berdasarkan Tabel 4 di atas dapat diketahui nilai yang mengalami penurunan atau selisih negatif adalah 9 dengan yang artinya 9 orang pasien terjadi penurunan nyeri setelah diberikan aromaterapi lavender. Hasil penelitian dari 16 responden yang dijadikan sampel terdapat 9 responden terjadi penurunan nyeri. Hal ini di sebabkan karena pemberian aromaterapi lavender yang bertujuan untuk meningkatkan toleransi terhadap nyeri, membuat nyaman dan rileks, mengurangi ketegangan tubuh sehingga nyeri berkurang.

Hasil nilai positive ranks atau selisih positif adalah 1 , artinya 1 orang pasien terjadi peningkatan nyeri setelah diberikan aromaterapi lavender.Kemudian terdapat 1 responden yang mengalami peningkatan nyeri. Hal tersebut dikarenakan kondisi psikologis yang membuat responden sendiri tidak fokus pada saat diberikan aromatrrapi lavender dan aromaterapi tersebut tidak bekerja secara maksimal dalam tubuh untuk mengurangi nyeri sehingga nyeri semakin meningkat.

Hasil nilai atau kesamaan nilai adalah 6 , artinya terdapat 6 orang pasien dengan intensitas nyeri yang sama antara sebelum dan setelah aromaterapi diberikan. Kemudian terdapat 6 responden yang nyerinnya menetap. Hal ini menunjukan karena ketika diberikan aromaterapi lavender persepsi responden tidak merasakan adanya efek dari aromaterapi tersebut sehingga penurunan intensitas nyeri yang dirasakan responden tidak berubah sama sekali.

Hasil uji Wilcoxon Sign Rankdidapat nilai $Z=-2,609$ dengan $p$ value $=0,009<0,05$ signifikan, maka Ho ditolak dan Ha diterima. Kesimpulan: Ada pengaruh aromaterapi lavender terhadap penurunan intensitas nyeri pada pasien post sectio caesarea di Ruang Tribrata RS Bhayangkara Kota Bengkulu.

\section{PEMBAHASAN}

Hasil penelitian ini menunjukan bahwa sebelum dilakukan pemberian aromaterapi lavender (pretest)terdapat 8 responden $(30 \%)$ dengan nyeri berat. Nyeri berat adalah nyeri yang berlangsung secara terus menerus sepanjang hari, sehingga tidak dapat tidur atau sering terjaga oleh gangguan nyeri sewaktu tidur.

Terdapat $3(31,2 \%)$ pasien post sectio caesarea yang mengalami nyeri ringan. Nyeri ringan adalah nyeri yang hilang timbul, terutama sewaktu melakukan aktivitas sehari-hari dan waktu tidur.

Kemudian terdapat $5(18,8 \%)$ pasien post sectio caesarea yang mengalami nyeri sedang. Nyeri sedang adalah nyeri terus menerus, aktivitas terganggu, yang hanya hilang apabila penderita tidur. 
Hasil penelitian tersebut sejalan dengan teori (Black \& Hawks, 2014) bahwa persepsi nyeri sangat subjektif, individu yang mengungkapkan nyerinya hanyalah yang mengalaminya sehingga tidak menutup kemungkinan intensitas nyeri yang sama dirasakan berbeda oleh individu yang berbeda. Selain itu terdapat beberapa faktor yang memengaruhi persepsi dan reaksi masing-masing individu terhadap nyeri. Faktor-faktor yang dapat berpengaruh adalah usia, jenis kelamin, perhatian, ansietas (kecemasan) dan keletihan.

Hasil penelitian ini menunjukan bahwa setelah dilakukan pemberian aromaterapi lavender (postest)terdapat $3(18,8 \%)$ pasien yang mengalami nyeri berat, $10(62,5 \%)$ pasien yang mengalami nyeri ringan, dan 3 $(18,8 \%)$ pasien yang mengalami nyeri sedang.

Penelitian ini sejalan dengan penelitiaan Kim (2017) menyebutkan bahwa penggunaan aromaterapi untuk perawatan post operasi anastesi dengan pemakaian aromaterapi lavender memiliki pengaruh yang signifikan dan lebih efektif dibandingkan dengan pemakaian sadatif. Selain itu hasil yang diperoleh mengenai penelitian ini yaitu pemakaian aromaterapi lavender lebih efektif dalam proses penurunan nyeri dibandingkan dengan pemakaian analgesik ( $p$-value $=0,007$ ).

Hasil penelitian dari 16 responden yang dijadikan sampel terdapat 9 responden terjadi penurunan nyeri.Hal ini di sebabkan karena pemberian aromaterapi lavender yang bertujuan untuk meningkatkan toleransi terhadap nyeri, membuat nyaman dan rileks, mengurangi ketegangan tubuh sehingga nyeri berkurang.

Kemudian terdapat 1 responden yang mengalami peningkatan nyeri. Hal tersebut dikarenakan kondisi psikologis yang membuat responden sendiri tidak fokus pada saat diberikan aromatrrapi lavender dan aromaterapi tersebut tidak bekerja secara maksimal dalam tubuh untuk mengurangi nyeri sehingga nyeri semakin meningkat. faktor lain yang menyebabkan terjadi peningkatan nyeri yaitu kondisi psikologis yang labil maka dari itu terjadi peningkatan nyeri pada responden tersebut. Hal ini sesuai dengan teori (Andarmoyo, 2013) faktor-faktor yanng mempengaruhi nyeri salah satunya adalah kondisi psikologis. Situasi dan kondisi psikologis yang labil memegang peranan penting dalam memunculkan nyeri persalinan yang lebih berat. Salah satu mekanisme pertahanan jiwa terhadap stress adalah konversi, yaitu memunculkan gangguan secara psikis menjadi gangguan fisik.

Kemudian terdapat 6 responden yang nyerinnya menetap. Hal ini menunjukan bahwa nyeri bersifat subjektif karena respon setiap orang terhadap nyeri dapat berbeda tergantung orang tersebut mempersepsikan walaupun dengan keadaan yang relatif sama.Setiap orang memiliki cara yang berbeda dalam mengatasi dan menginterpretasikan nyeri. Cara seseorang berespon terhadap nyeri adalah akibat dari banyak kejadian nyeri selama rentang hidupnya. Orang dewasa akan mengalami perubahan neurofisiologis dan mungkin mengalami penurunan persepsi sensorik stimulus serta peningkatan ambang nyeri (Potter \& Perry, 2012).

Hasil uji Wilcoxon Sign Rank didapat nilai $Z=-2,609$ dengan $p$ value $=0,009<0,05$ signifikan, maka Ho ditolak dan Ha diterima. Kesimpulan: Ada pengaruh aromaterapi lavender terhadap penurunan intensitas nyeri pada pasien post sectio caesarea di Ruang Tribrata RS Bhayangkara Kota Bengkulu.

Adapun penelitian yang dilakukan oleh Dina Misfonika, 2019 dengan judul "Efektivitas Aromaterapi Lavender Terhadap Tingkat Nyeri Pada Pasien Pasca Operasi Sectio Caesarea di RS Kusuma Ungaran" Berdasarkan hasil uji analisis dengan menggunakan uji paired t test dapat diketahui hasil p-value sebesar 0,000 $(<0,05)$ yang berarti ada perbedaan secara signifikan tingkat nyeri pasien pasca operasi section caesarea sebelum dan sesudah diberikan intervensi aromaterapi lavender. Pemberian aromatherapi 
lavender merupakan salah satu dari terapi komplementer berupa latihan teknik relaksasi pernapasan. Prinsip dasar teori penurunan nyeri oleh teknik relaksasi pernapasan menggunakan aromatherapi lavender adalah teori gate control yang terletak pada fisiologis sistem otonom. Tarik napas dalam dapat memberikan individu kontrol diri ketika terjadi rasa ketidaknyamanan atau cemas, stress fisik dan emosi yang menyebabkan nyeri meningkat, sehingga mendekatkan hubungan terapeutik perawat dan klien.

\section{KESIMPULAN}

Berdasarkan hasil penelitian Sebelum dilakukan pemberian aromaterapi lavender terhadap penurunan intensitas nyeri pada pasien post section caesarea pasien nyeri berat berjumlah 8 orang (30\%), pasien nyeri sedang berjumlah 5 orang $(31,2 \%)$, dan pasien nyeri ringanberjumlah 3 orang $(18,8 \%)$.

Setelah dilakukan pemberian aroma terapi lavender terhadap penurunan intensitas nyeri pada pasien post section caesarea pasien nyeri berat berjumlah 3 orang $(18,8 \%)$, pasien nyeri sedang berjumlah 3 orang $(18,8 \%)$, dan pasien nyeri ringan berjumlah 10 orang $(62,5 \%)$.

Ada pengaruh pemberian aromaterapi lavender terhadap penurunan intensitas nyeri pada pasien post section caesarea.

\section{DAFTAR PUSTAKA}

Amita, D., Fernalia, F., \& Yulendasari, R. (2018). Pengaruh Teknik Relaksasi Nafas Dalam Terhadap Intensitas Nyeri Pada Pasien Post Operasi sectio caesarea Di Rumah Sakit Bengkulu. Holistik Jurnal Kesehatan, 12(1), 26-28.

Anwar, M., Astuti, T., \& Bangsawan, M. (2018). Pengaruh Aromaterapi Lavender terhadap Penurunan Intensitas Nyeri Pasien Paska Operasi Sectio Caesarea. Jurnal
Ilmiah Keperawatan Sai Betik, 14(1), 84-90.

Aprina, A., Hartika, R., \& Sunarsih, S. (2018). Latihan Slow Deep Breathing dan Aromaterapi Lavender terhadap Intensitas Nyeri pada Klien Post Seksio Sesaria. Jurnal Kesehatan, 9(2), 272-279.

Astuti. D. (2019). Hubungan Nyeri Luka

Post Sectio Caesarea Dengan Kualitas Tidur Di RSUD Dr. $H$. Abdul Moeloek Provinsi Lampung. Program S1 Keperawatan Sekolah Tinggi Ilmu Kesehatan(STIKES) Muhammadiyah Lampung.

Damayanti, R. (2019). Pengaruh Musik Klasik Terhadap Tingkat Nyeri Luka Dan Produksi Asi Pada Pasien Post Sectio Caesarea Di RST dr. Soejono Magelang. Program Studi Ilmu Keperawatan Fakultas Kesehatan Universitas Muhammadiyah Magelang.

Haqiqi, B. R. (2016). Perbedaan Perubahan Tingkat Nyeri Persalinan Normal Antara Kelompok Dengan Dan Tanpa Aromaterapi Lavender Di Lamongan. Program Studi Pendidikan Bidan Fakutas Kedokteran Universitas Airlangga Surabaya.

Haslin, S. (2018). Pengaruh Aromaterapi Lavender Terhadap Penurunan Intensitas Nyeri Pada Persalinan Primigravida Kala I Fase Aktif Di Klinik Pratama Tanjung Kec. Deli Tua. Prodi D-IV Kebidanan Jurusan Kebidanan Politeknik KesehatanMedan.

Marcela, R. P. (2018). Asuhan Keperawtan Pada Ibu Post Sectio Cesarea Dengan Masalah Nyeri Akut Menggunakan Aromaterapi Lavender Di Ruang Mawar RSUD Abdul Wahab Syahranie Samarinda. Program Studi D3 Keperawatan Politeknik Kesehatan Kalimantan Timur.

Misfonica,

D. (2019). EfektivitasAromaterapi Lavender 
Terhadap Tingkat Nyeri Pada Pasien Pasca Operasi Sectio Caesarea Di Rumah Sakit Kusuma Ungaran (Doctoral dissertation, Univerisitas Ngudi Waluyo).

Nasution, M. A. (2020). Pengaruh Terapi Stress Ball terhadap Kecemasan padaPasien Pre Sectio Caesarea. Fakultas Keperawatan Universitas Sumatera Utara

Oktaverina, D. I. N. (2020). Pengaruh Terapi Musik Klasik Terhadap Penurunan Skala Nyeri Post Operasi Sectio Caesarea Pada Ibu Nifas Di Gema II Rs. Dirgahayu Samarinda. Jurusan Kebidanan Prodi Sarjana Terapan Kebidanan Politeknik Kesehatan Kalimantan Timur.

Putri, M. T., Aditama, D. S., \& Diyanty, D. (2019). Efektivitas aromaterapi sereh (cymbopogon citratus) dengan teknik relaksasi genggam jari terhadap penurunan nyeri pasca sectio caesarea. Wellness And Healthy Magazine, 1(2), 257-276.

Sitepu, R. A. A. BR. (2021). Hubungan Penggunaan Aromaterapi Dengan Penurunan Nyeri Kepala Primer Pada Mahasiswa Fakultas Kedokteran Universitas Sumatera
Utara. Program Studi Pendidikan Kedokteran Dan Profesi Dokter Fakultas Kedokteran Universitas Sumatera Utara.

Viviyani, T., Wulandari, D., \& Rahmadani, E. (2019). Pengaruh Dzikir Terhadap Skala Nyeri Pada Ibu Post Partum Sectio Caesarea di RSUD dr. M. Yunus bengkulu tahun 2019. Journal of Nursing and Public Health, 7(2), 92-102.

Wahyu, H., Febriawati, H., Lina, L. F., Andari, F. N., \& Wulandari, R. (2019). Pengaruh Terapi Kompres Hangat dengan Aroma Lavender terhadap Penurunan Intensitas Nyeri pada Pasien Post Sectio Caesarea di RS. Detasemen Kesehatan Tentara (DKT) Bengkulu. Jurnal Keperawatan Muhammadiyah Bengkulu, 7(1), 18-26.

Zuraida, Z., \& Keta, D. P. (2020). Pengaruh Kombinasi Yoga dan Aroma Terapi Lavender Terhadap Tingkat Nyeri Dismenore pada Remaja Putri di Pondok Pesantren Sumatera Thawalib Parabek. Maternal Child Health Care, 2(2), 151-162. 